
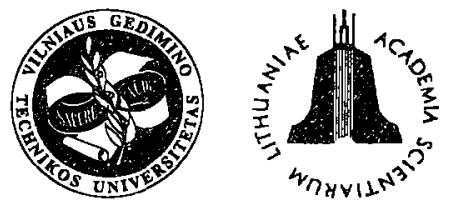

ISSN 1648-4142 TRANSPORT

http:/www.vtu.lt/english/editions

TRANSPORT-2002, Vol XVII, No 3, 117-12I

\title{
MODELLING OF INTERMODAL FREIGHT TRANSPORTATION NETWORK
}

\author{
Aidas Vasilis Vasiliauskas \\ Department of Transport Management, Vilnius Gediminas Technical University, Plytines 27, LT-2040 Vilnius, \\ Lithuania, Tel. (370) 2 315605.E-mail: avv@mail.lt
}

Received 200202 02; accepted 20020418

\begin{abstract}
It was realized long ago that one of the main factors for steady groowing economic of the country is a properly working transport system in which new enough means of cargo transportation, so called intermodal transportation takes not the last place. First of all it raises problems related with the development and optimization of proper infrastructure the network of roads and terminals which aim to carry out intermodal transportation.

The article deals with one of possible ways of modelling the national intermodal freight transportation network.

The basis for such model is the investigation of freight traffic during which we identify the routes for intermodal freight transportation (as well as places where such freight is shifted from one mode of transport to another), extend the existing statistic date base on modal transport carriages and start to develop a new data base on intermodal freight carriages. With the help of the last one we can go further in modelling national intermodal freight transportation network and determine the steps for creating such network. The main steps should include:

- the integration of the particular modal networks into a general intermodal network;

- the optimization of the network defining optimal routes between possible origin and destination points;

- the estimation of terminal operations to get a more detailed and optimal view of the national intermodal cargo transportation network.
\end{abstract}

Keywords: intermodal transport, modal transport networks, modelling of intermodal transport networks, investigation of freight traffic.

\section{Introduction}

In recent decades the transportation of goods has grown in Europe, thus making the efficient freight transportation system a major component of highly developed economy. In this respect the efficiency of intermodal transportation is often mentioned [1]. Intermodal transportation is usually referred to as transporting of a particular cargo by various transport facilities without transfer [2]. In Lithuania this type of transportation is associated with the transporting of goods through the Klaipeda sea port combining railroad - road, road - sea and railroad - sea transport as well as the networks of respective modal infrastructures and cargo transfer terminals $[1,2]$.

The new types of transport facilities, freight containers and their handling technologies widely extend the potentialities of intermodal transportation [1-3], thus making the intermodal network modelling a basic element of further development in this area $[1-3]$.

A major goal of the presented paper is to provide one of the alternative variants of developing national network of intermodal freight transportation.

\section{Investigation of Freight Traffic}

The network considered should embrace the modal freight transportation infrastructure from the departure and destination points (having some indices) in Lithuania and abroad. For this purpose freight traffic should be investigated with the aim to establish the number of operators and the way they use the intermodal transportation in the country and for exporting goods [4]. A survey would require the data of operators on:

a) the points of departure and destination of the trip; b) the types of transported goods, their tonnage and value;

c) the sequence of using various transport facilities.

The results of the research would make the basis for freight transportation map plotting, showing the routes of intermodal transportation and the places of transport facilities change. To achieve this a computer - aided program for the research data processing and presentation in the form available for the user should be developed $[4,5]$. However, this is not the issue discussed in the presented paper. The problem of developing the national intermodal transportation network showing the routes in compliance with those obtained in the reports on goods traffic investigation is considered. The relevance of goods traffic research is primarily for storing the data on intermodal freight transportation between the starting and terminal points $[1,4]$. It is important because the data at the disposal of 
the authorities are based only on the transportation performed by particular transport facilities between the departure and destination points. This means that the geography and intermodality of freight transportation are not laken into account $[3,6]$. The study of goods traffic would fill the gap, as well as provide the information about the modal freight transportation. Therefore, the research considered could provide the basis for solving the problems of developing and presenting the intermodal freight transportation network as follows :

a) development of intermodal network investigating various modal networks ;

b) finding the terminals closest to the points of departure and destination, allowing the intermodal network optimisation;

c) assessing terminal operation in the context of the whole network in order to obtain the most adequate view of the intermodal freight transportation network $[1,4]$.

\section{The Development of an Intermodal Transportation Net- work}

The development of a general network would include the integration of the particular modal networks into a unified system, ensuring the intermodal transportation between any two network points denoted by certain indices [1]. Thus, an integral network would be developed allowing any combination of intermodal routes sequences. All the links of the network represent actual roads of cer- tain geographical location specified in freight traffic investigation reports $[1,4]$. A general network will be created connecting the networks of particular transport facilities via a number of road - railroad (RR), road - waterway (RW), and railroad - waterway (RRW) transport terminals. This concept is illustrated in Fig 1 for the interaction of road and railroad transport networks $[1,7]$.

The network development proceeds connecting the first road transport network and the network of railroad transport via the first RR terminal, and then back to the second road transport network through the second $R R$ terminal.

The use of the required transport facilities at a particular stage of transportation will be provided in the following way. At the beginning all the components of the intermodal network are "tumed off". It is assumed that any transport facility is used in its turn at the required moment. Then the first part of the intermodal network is "activated" which is the 1 - st road transport network with RR terminal closest to the starting point denoted by a particular index. In the next section, we will consider the problem of finding such a terminal. In a similar way, the terminal for getting to the 2 - nd road transportation network is found. The part of the route for railroad transportation is inserted between the first and the last road transport networks via the corresponding RR terminals. Thus, the intermodal terminals located along a particular route close to particularly indexed departure and destination points ensure the proper sequence of using the available

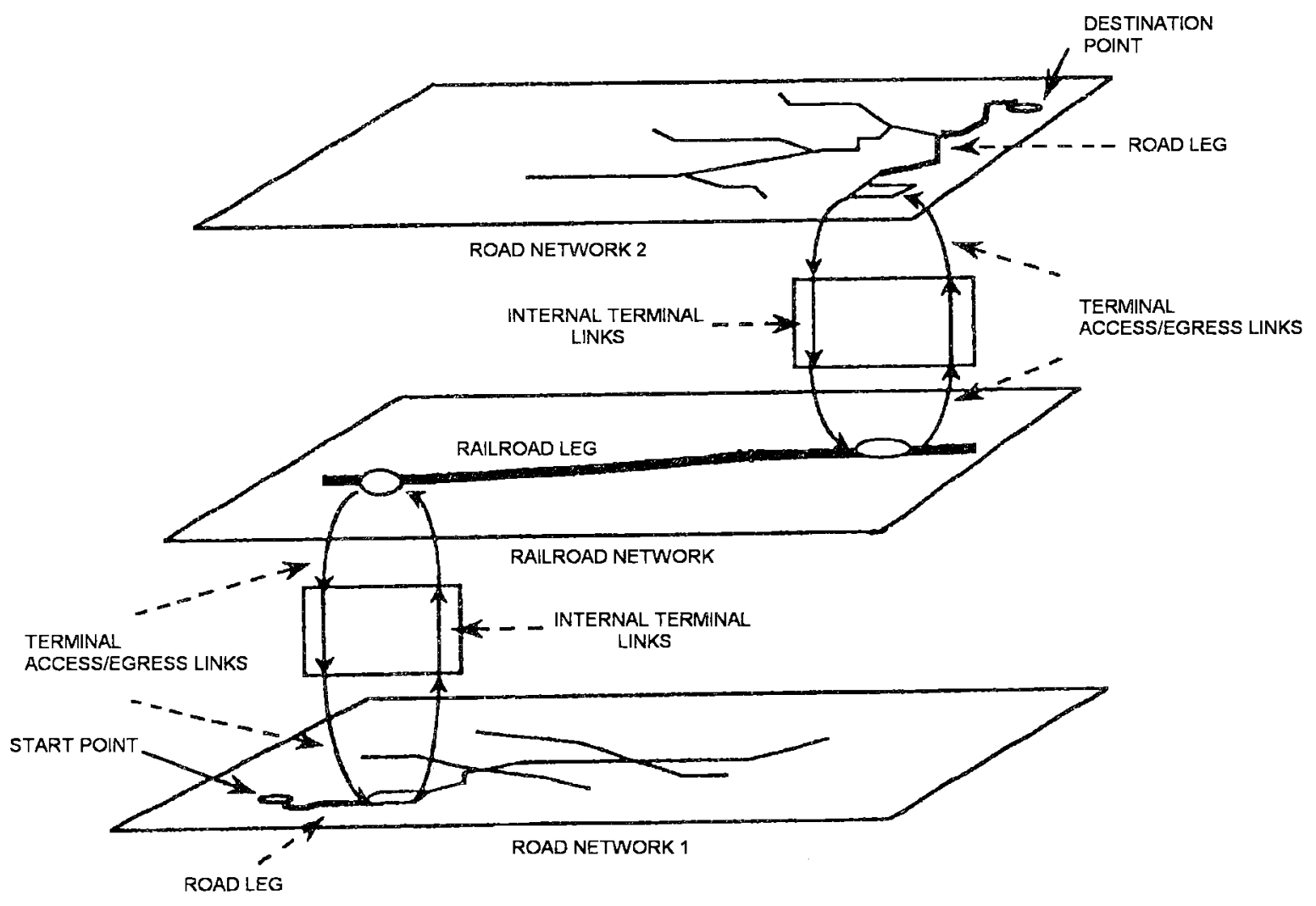

Fig 1. Integration of the particular modal networks into a general intermodal network 
transport facilities. By the way, in cargo transfer at the terminals, some additional entrance/ exit links, not belonging to any of the modal networks making a general intermodal network, should be taken into account. This is also shown in Fig 1 and discussed in section 5.

When individual modal networks and terminals connecting them, which have their own entrance/exit links with a particular modal network, have been taken into consideration, we obtain a general geographical view of an intermodal network [1].

The problems which may arise with respect to the above visual network presentation are as follows:

a) a large number of links may appear to be of zero length, since they represent a process taking place at a point (i.e. cargo transfer at a terminal),

b) some objects may overlap (i.e. terminals for freight handling located at the same geographical area) [8].

To avoid these problems a possibility should be provided in developing a network to alter slightly the location of the points in such a way as to avoid placing of two objects in the same geographical area. This could provide certain length for the link as well as avoid overlapping of the objects.

\section{Determining the Terminals Nearest to Starting and Destination Points in Transportation}

In order to begin working out the routes for freight transportation every individual modal network should be slightly modified to be integrated into a general network. In addition, the inclusion of such specific links as railroad access tracks and approaches to terminals, the information of which is not provided anywhere, requires some modification. The networks of particular transport facilities should be modified in the following way:

1. In representing road transport networks, the corresponding road transport terminals, acting as the ways of intermediate stops in the route, should be taken into account. The approaches to such terminals should be handled as some additional links in a network.

2. Water transport network should be divided into two smaller, but closely related subsets. They are the network of the inland water transport and sea transport, in which different types of ships are used. It is important to identify the locations of cargo transfer from the ships of various types, adding special links to a general network in these places.

3. In railroad transport, the fact that various railroad operators can operate on particular railroad lines should be taken into account. This is important, because the operators transporting cargoes to various countries greatly extend the geographical data base of transportation as well as increasing the number of additional links.

In addition, railroad and road transport networks should be extended to embrace major roads of the neighbouring countries by connecting them to Lithuanian internal transportation networks. This should be achieved by adding new links at the points of crossing the border.

Having made the appropriate modifications, a rather accurate view of an intermodal transportation network would be obtained. However, to make it optimal, one or more terminals nearest to a starting or terminal points of the route, provided with the particular indices, should be determined. For this purpose, a formula is used to find a radius, at the range of which with respect to the indexed starting point of the trip the required area could be found, with the terminals on it to be used as entrance/exit points to/from the intermodal network:

$$
R_{\max }=R_{z}+(2 e)+p
$$

Here, $R_{\max }$ - radius of searching for the network entrance/exit points (terminals); $R_{2}$ - the shortest distance from the point having a particular index to an arc of a circle described by a search radius; $e$ - the least root - mean square error in determining the location; $p$ - maximum length of entrance/exit links to/from the network, not entered into modal infrastructure data base of a particular transport facility.

Experimentally obtained $e$ and $p$ values for the particular transport facilities are presented in Table.

Applying the formula (1) maximum search radius from an indexed starting or terminal point of the trip could be found for any transport facility with all the terminals in the range of this radius being the potential entrance/exit points to/from the intermodal network.

It should be noted that the search for the terminal varies slightly, depending on the type of transport facility:

a) in case of relatively dense road trasnport network, the value of $p$ is equal to zero (Table). Thus, most optimal terminals are determined drawing the straight line from the centre with a particular index to the nearest road transport network located in each $120^{\circ}$ sector. The most optimal terminal will be such, the distance to which is the shortest (in this case, it is terminal A in sector 1). The whole searching procedure is shown in Fig 2.

b) Fig 3 illustrates the application of formula 1 to railroad transport.

The values of the parameters e and $\mathrm{p}$ for particular transport facilities, $\mathrm{km}$

\begin{tabular}{|c|c|c|c|c|}
\hline Parameter & Roads & Railways & Inland waterways & Sea \\
\hline $\mathrm{p}$ & 0,00 & 8,00 & 8,00 & 10,00 \\
\hline $2 \mathrm{e}$ & 0,35 & 3,00 & 3,00 & 3,00 \\
\hline
\end{tabular}




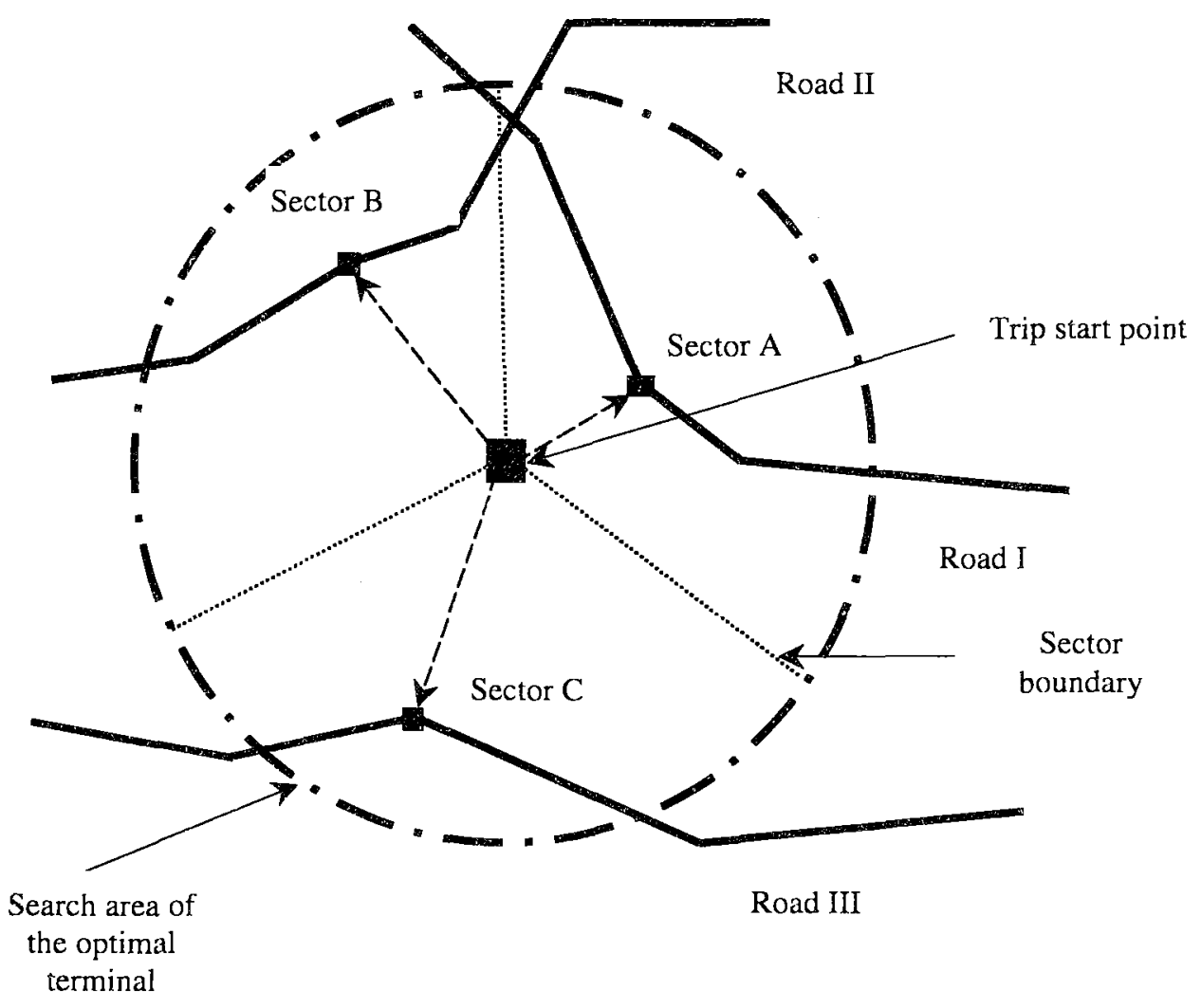

Fig 2. The search for the optimal terninal in road transport network

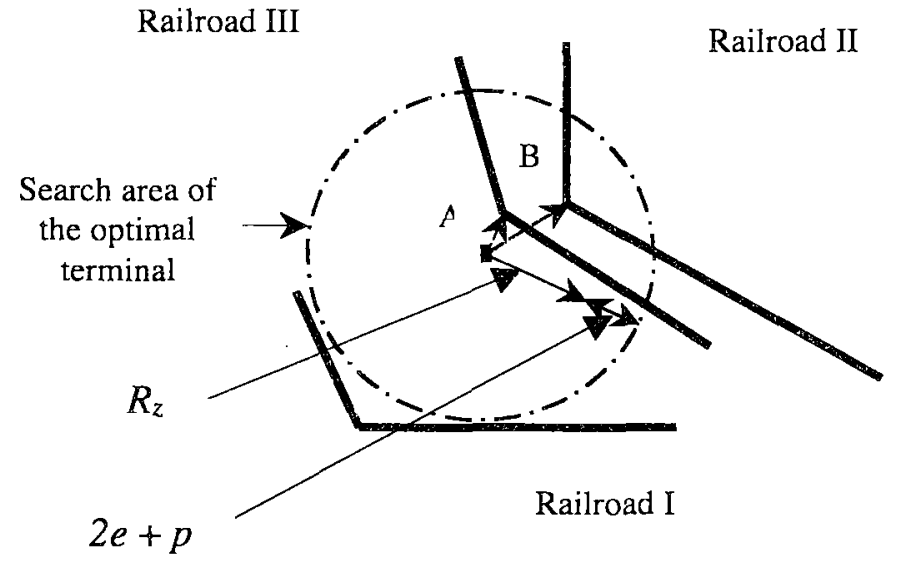

Fig 3. The search for the optimal terminal in railroad transport network

c) most optimal terminal in inland water transport network may be determined in a similar way as that for railroad transport.

\section{Assessment of Terminal Operations in Detailed pre- sentation of Intermodal Network}

In section 3 it was mentioned that, developing an intermodal network out of individual modal networks, the areas for linking the above network where cargo transfer would take place, should be provided. To obtain more detailed view of the network a terminal should be presented (and assessed) as a separate link. In Fig 4 two possible variants of terminal presentation and evaluation in a general network are given.

One of them (Fig 4a) may be referred to as a bimodal link method because each cargo transfer operation is represented as the only additional link between two different 


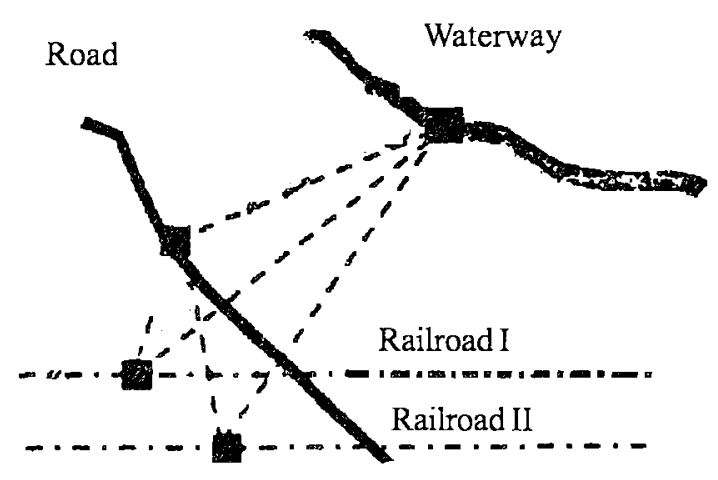

a)

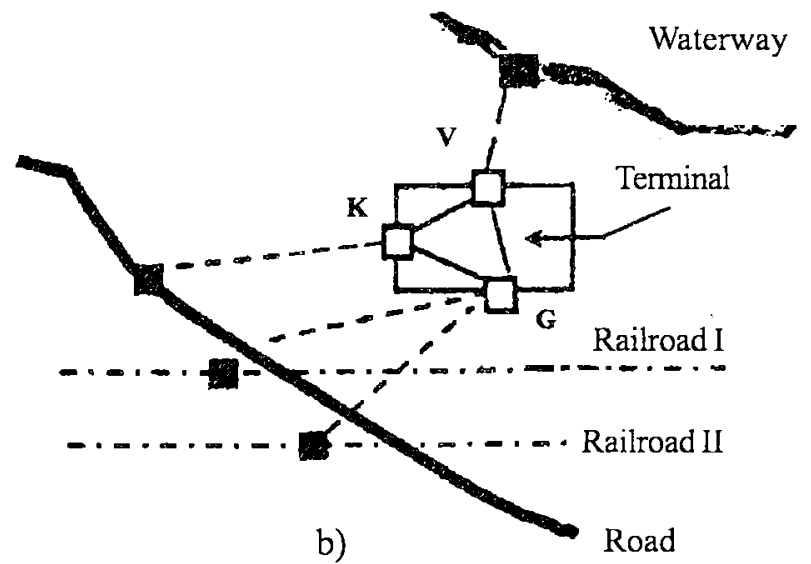

b)

Fig 4. Two ways available for terminal operation modelling

transport facilities (they are shown by a dotted line in the picture). This would be the easiest solution, allowing a number of links of a particular direction to be related to a separate modal network of transport facility.

Another approach to considering and representing terminal operations is shown in Fig 4b. In this case a transport terminal located in a certain geographical area is considered together with the actual entrance/exit links to/from the corresponding modal network (they are shown by single dotted - lines leading to the entrance gate of the terminal, denoting $\mathrm{V}$ - water, $\mathrm{K}$ - road, and $\mathrm{G}$ - railroad transport, respectively). It should be noted that for the $1-$ st type of transport more than one entrance gate may exist. This more complex variant is particularly effective for the situation when modal networks are rather rare, requiring sufficiently long entrance links to integrate the terminals into a general network. It is also important in areas where the gates face various directions.

\section{Conclusions}

1. One of the available models of developing national intermodal freight transportation network has been considered. It is based on the analysis of freight traffic, providing the initial data for model development. Currently available statistical data on modal freight transportation has been extended and some data for a new data base on intermodal freight traffic have been stored.

2. Based on the data of the present research, a model of Lithuania internodal freight transportation network may be developed and applied to practical needs.

3. Due to the universal character of the data collected and the use of simple algorithms modelling may be performed in three stages aimed:

- to develop an intermodal network connecting individual modal networks into an integral system;

- $\quad$ to optimise the network identifying optimal freight handlling terminals for any starting or terminal point of the trip mentioned in goods traffic survey;

- to evaluate the processes taking place in the termi- nal, thereby optimising the operations performed as well as presenting most adequate and detailed view of the intermodal network.

\section{References}

1. Southworth F., Peterson B.E. Intermodal and international freight network modelling. Transportation Research Part C, No 8, 2000, p 147-166.

2. Baublys A. Transportation of freight (Krovinių vežimai). Vilnius: Technika. 1998. $357 \mathrm{p}$ (in Lithuanian).

3. Friesz T.L., Gottfried J. A., Morlok E. K. A sequential shipper-carrier network model for predicting freight flows Transportation Science, No 20, 1986, p 80-91.

4. Southworth F., Peterson B. E., Chin S-M. Methodology for estimating freight shipment distances for the 1997 commodity flow survey. In: Report prepared for the Bureau of Transportation Statistics. US Department of Transportation. Washington DC. 1998. 32 p.

5. Boardman B. S., Malstrom E. M., Butler D. P., Cole M. H. Computer assisted routing of intermodal shipments. Contputer and Industrial Engineering, No 33, 1997, p 311-314.

6. Statistical yearbook of Lithuania. Statistic Department of goverment of Lithuania Republic (Lictuvos statistikos metraštis. Statistikos departamentas prie Lietuvos Respublikos Vyriausybès). V., 2001. 636 p (in Lithuanian).

7. Ferreira L., Sigut J. Measuring the performance of intermodal freight terminals. Transportation Planing and Technology, No 17,1993, p 269-280.

8. Benjamin Zhan F., Noon C. E. Shortest Path Algorithms: An Evaluation using Real Networks. Transportation Science, Vol 32, No 1, 1998, p 65-73. 